Cahiers $d u$ MONDE RUSSE

\section{Cahiers du monde russe}

Russie - Empire russe - Union soviétique et États indépendants

$51 / 4 \mid 2010$

Sciences humaines et sociales en Russie à l'Âge d'argent

\title{
David B. Miller, Saint Sergius of Radonezh
}

\section{Florent Mouchard}

\section{(2) OpenEdition}

1 Journals

\section{Édition électronique}

URL : https://journals.openedition.org/monderusse/7364

DOI : 10.4000/monderusse. 7364

ISSN : $1777-5388$

Éditeur

Éditions de l'EHESS

\section{Édition imprimée}

Date de publication : 25 novembre 2010

Pagination : 678-681

ISBN : 978-2-7132-2316-7

ISSN : $1252-6576$

Référence électronique

Florent Mouchard, «David B. Miller, Saint Sergius of Radonezh », Cahiers du monde russe [En ligne], 51/4 | 2010, mis en ligne le 09 décembre 2011, consulté le 02 septembre 2022. URL : http:// journals.openedition.org/monderusse/7364; DOI : https://doi.org/10.4000/monderusse.7364

Ce document a été généré automatiquement le 2 septembre 2022

Tous droits réservés 


\title{
David B. Miller, Saint Sergius of Radonezh
}

\author{
Florent Mouchard
}

\section{RÉFÉRENCE}

David B. MILLER, Saint Sergius of Radonezh. His Trinity Monastery, and the

Formation of the Russian Identity. DeKalb, IL : Northern Illinois University Press, 2010, $348 \mathrm{p}$.

1 Comme dans d'autres sociétés médiévales, le sentiment d'appartenance en Moscovie s'est développé dans une étroite compénétration entre le facteur proprement politique, le social et le religieux, souvent autour de grandes figures tutélaires. Le saint, et donc le culte qui lui est rendu, apparaissent ainsi comme un foyer de cohésion et une voie d'accès privilégiée à l'identité d'une communauté. C'est pourquoi son étude est l'un des thèmes centraux de l'histoire de la Moscovie prémoderne.

2 Parmi les saints de cette période, Serge de Radonež est particulièrement bien placé. Saint majeur de l'Église orthodoxe russe, figure centrale du XIV ${ }^{\mathrm{e}}$ siècle, il est mêlé de près ou de loin à bien des grandes tendances de l'époque : sa famille est témoin (et victime) de l'expansion territoriale des princes de Moscou; lui-même joue un rôle central dans le grand mouvement de réforme monastique dirigé par les métropolites Alexis et Cyprien, et participe de près aux jeux politiques des princes et des hiérarques de l'Église. Il n'est donc pas surprenant que les historiens se soient intéressés à Serge, depuis les grands noms du $\mathrm{XIX}^{\mathrm{e}}$ siècle (Golubinskij, Ključevskij, Solov'ëv et bien d'autres) jusqu'aux spécialistes d'aujourd'hui, tant russes qu'étrangers.

3 La parution d'une nouvelle monographie consacrée à Serge s'inscrit donc dans une longue tradition historiographique. Mais cet ouvrage est, semble-t-il, le premier à aborder dans le cadre d'une seule problématique la vie de Serge, d'une part, et celle de sa fondation à travers les siècles, d'autre part ; c'est là ce qui fait tout son intérêt. L'auteur, David B. Miller, professeur émérite d'histoire de la Russie à l'université Roosevelt de 
Chicago, a choisi une approche sociologique assez durkheimienne, dans la lignée d'Aviad Kleinberg (professeur d'histoire médiévale à l'université de Tel-Aviv, auteur de travaux reconnus sur la sainteté au Moyen-Âge). Cette démarche peut être résumée par une phrase tirée de l'introduction (p. 6) : « Sainthood emerges out of an ongoing negotiation between the candidate's promoters on one hand and succeeding generations with their baggage of aspirations and expectations on the other ».

La communauté des disciples de Serge, réunie au monastère de la Trinité autour de l'abbé Nikon et de l'hagiographe Épiphane le Sage, apparaît donc, dans cette perspective, comme l'interface fondamentale entre le fondateur et, plus tard, ceux qui le vénèrent. David Miller lui consacre deux chapitres (p.42-75, 76-104), où il analyse le développement du culte de Serge et ses rapports avec le pouvoir politique. Le monastère agit en effet, selon l'auteur, comme élément fédérateur de la communauté qui s'y retrouve pour prier Dieu et implorer l'intercession du saint, depuis les différents monarques jusqu'aux pèlerins vagabonds de la plus humble origine ; ainsi, sa part dans la prise de conscience permanente de la Russie par elle-même est réellement éminente, plus sans doute que pour d'autres monastères. Mais la Trinité joue aussi son rôle dans la formation idéologique de l'empire moscovite ; pour ne citer qu'un exemple, David Miller revient longuement (p.63-69) sur un épisode clé de la Vie de Serge, mais aussi des chroniques des $\mathrm{XV}^{\mathrm{e}}-\mathrm{XVI}^{\mathrm{e}}$ siècles, celui de la visite qu'aurait rendue Dmitrij Donskoj au saint, au moment de se mettre en campagne contre Mamaj en 1380. L'auteur pose à juste titre la question de l'historicité de l'épisode, en rappelant qu'on ne le trouve nulle part, semble-t-il, avant la version de la Vie rédigée par Pacôme le Logothète (vers 1420-1450), et en particulier que les fragments reconstitués de la Chronique de la Trinité, qui pourtant mentionnent Serge à plusieurs reprises, ne soufflent mot de son rôle en 1380 ; sans compter d'autres considérations qu'il convient de prendre en compte, comme le fait que la Trinité ne se situe pas dans le domaine de Dmitrij Donskoj, ou - le plus important, sans doute - que la situation conflictuelle de la métropole, liée à la crise qui suit la mort du métropolite Alexis, aurait difficilement permis une telle visite. Cependant, quoi qu'il en soit de son historicité, l'épisode devient par la suite l'un des schémas narratifs fondamentaux par lesquels s'exprime une vision idéalisée des rapports entre Église et État.

5 Mais David Miller ne s'est pas arrêté à ces questions et, pour mesurer les fluctuations et l'évolution de la « négociation permanente » entre la société et le monastère, il a établi une base de données chiffrée - qui donne ainsi toute leur solidité aux résultats de son enquête. Il s'explique en introduction (p. 7-8) sur les principes qui l'ont guidé. L'auteur interroge ensuite sa base de données sous divers angles, qui sont autant de chapitres particuliers. Le ch. IV, «Trinity's Patrons» (p. 107-137), s'étend sur la " community of venerators" et le système des donations de biens immobiliers à la Trinité. Une proportion notable des familles aristocratiques recourt en effet à cette pratique tout au long des $\mathrm{XV}^{\mathrm{e}}-\mathrm{XVI}^{\mathrm{e}}$ siècles (comme d'ailleurs par la suite), créant ainsi un réseau aussi solide qu'étendu, qui implante la Trinité au cœur de la société moscovite. L'auteur s'attache ainsi à reconstituer les motivations des donateurs (obtention de la vie éternelle par les prières des moines, implication de la famille survivante dans la relation avec eux, p. 110), évolution des donations à travers la période considérée et les facteurs qui l'influencent (p.118-123), enfin typologie sociale exacte des donateurs (p.123-128: propriétaires terriens $-47 \%$, clercs entre 10 et $20 \%$ ). David Miller esquisse à plusieurs reprises des parallèles bienvenus avec l'histoire ouest-européenne, particulièrement avec la France 
des $\mathrm{IX}^{\mathrm{e}}-\mathrm{X}^{\mathrm{e}}$ siècles - qui n'est hélas toutefois connue qu'à travers l'historiographie américaine.

6 Le ch. V, «Trinity's Monks » (p. 137-168), repose sur un vaste travail prosopographique réalisé par l'auteur (voir en particulier p. 139-141, 153 sq., 160 sq.). Le lecteur y trouvera d'utiles données sur le nombre des moines et ses fluctuations à diverses époques, leur différenciation par origine géographique et sociale (même si l'effort de répartition semble parfois un peu trop systématique), ainsi que sur l'organisation des offices et leur évolution jusqu'en 1605 (abbé, cellérier, etc.), l'influence des facteurs extérieurs sur le recrutement ; ainsi (p. 160 sq.) l'opričnina des années 1565-1572 a pour effet de diminuer la part des élites aristocratiques dans la quantité globale des moines. L'auteur note justement que sous le règne d'Ivan III, la part des personnes d'origine aristocratique augmente notablement parmi les moines, au risque de mettre en danger le régime cénobitique du monastère; l'un des signes en est la lettre du métropolite Philippe $\mathrm{I}^{\mathrm{er}}$ à l'abbé Spiridon (21 mai 1472) ; mais le passage que cite Miller n'est pas compris, lorsqu'il écrit (p. 147): «Filipp admitted that the monastery "invited persons [into the brotherhood] according to their property" (priglašati vsja po imeni), according to the Holy Scripture». Il s'agit effectivement d'une citation de l'Évangile (Jn 10,3), cependant le métropolite parle non pas d'inviter les moines selon leurs biens, mais exhorte l'abbé à les connaître par leur nom, comme le Bon Pasteur appelle ses brebis ${ }^{1}$. Cette légère erreur matérielle n'enlève d'ailleurs rien au fond du propos.

7 Les chapitres IV et V présentent ainsi une sorte de vue d'ensemble, grâce à leur angle de vue assez large. Les deux suivants gardent la même amplitude chronologique, mais concentrent quelque peu leur problématique. Le ch. VI est consacré aux "Trinity's Female Venerators» (p. 169-202). L'auteur développe ici deux directions de recherche: «How the cult of St. Sergius and the monastery that maintained it gave meaning to the lives of women - and how women found ways to act in the public sphere by embracing the cult - is the subject of this chapter» (p.169). Ce type de problématique, bien balisé dans l'historiographie, est néanmoins encore novateur pour le champ des études médiévales russes, et doit donc être salué en tant que tel. Les femmes des lignées aristocratiques qui entourent la Trinité de leurs attentions ont en effet un rôle qui ne se limite pas à faire dire des messes pour leurs maris et parents défunts (605 des 4217 actes de donation conservés émanent par exemple de femmes).

8 Enfin, le ch. VII (p. 203-217) aborde plus succinctement la question de l'« Interment at Trinity ». Outre les moines, un certain nombre de laïcs ont en effet au cours des âges demandé à être enterrés à la Trinité, pour bénéficier de la sacralité du lieu. Dans la ligne des recherches de L. Steindorff sur le culte des morts dans l'ancienne Russie ${ }^{2}$, David Miller propose une analyse circonstanciée de ces requêtes; on y apprend ainsi que le maximum tombe sur la fin de la période considérée (1565 et après), ceci non sans lien avec l'histoire politique. L'opričnina eut en effet une conséquence méconnue: l'augmentation de dons de terrains au monastère, en échange de quoi les moines devaient prier pour le repos de l'âme des victimes (p. 206-207).

Voici donc un livre solide et utile, qui rendra des services aux spécialistes de la Russie moscovite; plus largement, il pourra intéresser aussi bien les médiévistes que les chercheurs travaillant sur d'autres périodes de l'histoire des Slaves orientaux. 


\section{NOTES}

1. Cf. le texte du métropolite Philippe, dans l'édition d'A.S. Pavlov, Pamjatniki drevne-russkogo kanoničeskogo prava, vol. 1 (Pamjatniki XI-XV v.), SPb., 1880, col. 735 (Russkaja istoričeskaja biblioteka, 6) : « И СЪ БЛАГОСЛОВЕНИЕМЪ НАШИМЪ УСТРОЕ[НЪ] ЕСИ ЯКО ДОБРЪ ПАСТЫРЬ СЛОВЕСНЫХЪ ЕГО ОВЕЦЬ, ИХЪЖЕ ТИ, СЫНУ, ЛЪПО ЕСТЬ... УЧИТИ... И ПО СВЯТОМУ ЕУАНГЕЛЬЮ ПРИГЛАШАТИ ВСЯ ПО ИМЕНИ ».

2. Ludwig Steindorff, Memoria in Altrußland: Untersuchungen zu den Formen christlicher Totensorge, Stuttgart : Franz Steiner, 1994 (Quellen und Studien zur Geschichte des östlichen Europa, 38). 